\title{
Macrocystis mariculture in Chile: growth performance of heterosis genotype constructs under field conditions
}

\author{
Renato Westermeier • David J. Patiño • Pedro Murúa • \\ Dieter G. Müller
}

\begin{abstract}
Recent progress in Macrocystis mariculture is based on clonal stock cultures of gametophyte parents. Batches of up to $10^{5}$ genetically identical sporophyte seedlings can be produced at any time in the laboratory and explanted in the field for production of biomass. Sexual crosses of selected Macrocystis pyrifera gametophyte parents of different geographic origin along the coast of Chile showed heterosis and produced sporophyte batches with superior growth performance. Starting from zygotes, after 10 weeks in the laboratory and 5 months in the sea, our best hybrid genotypes grew up to $11 \mathrm{~kg}$ fresh weight per frond, which corresponds to $66 \mathrm{~kg} \mathrm{~m}^{1}$ of line in a commercial mariculture installation. In contrast, average yields of 14.4 and $22 \mathrm{~kg} \mathrm{~m}^{1}$ are reported in the literature for traditional methods. Additional experiments, including inter-specific crosses $M$. pyrifera $\times M$. integrifolia and their performance in different climate zones of Chile, confirm that heterosis is a powerful tool for crop improvement in Macrocystis. It opens the possibility to construct tailor-made heterosis genotypes with maximum productivity and/or other desired properties for any given locality.
\end{abstract}

Keywords Biomass · Chile · Cross-breeding · Heterosis · Macrocystis $\cdot$ Mariculture

R. Westermeier $(\bowtie) \cdot$ D. J. Patiño $\cdot$ P. Murúa Instituto de Acuicultura, Universidad Austral de Chile, Campus Puerto Montt, Casilla 1327,

Puerto Montt, Chile

e mail: rwesterm@uach.cl

D. G. Müller

Fachbereich Biologie der Universität Konstanz,

78457 Constance, Germany

\section{Introduction}

Macrocystis (giant kelp) is an important natural resource in the coastal waters of Chile. Dried material is used for alginate production, while fresh fronds are harvested in large quantities as food for mariculture of herbivorous highvalue mollusks (abalone, Haliotis rufescens and H. discus hannai). Intense harvesting pressure on natural kelp beds has led to over-exploitation damage (Vásquez 2008). This situation calls for efforts to supplement the available kelp biomass by laboratory-based culture methods.

Traditional mariculture techniques make use of meiospores from natural populations, which are collected and manipulated to settle on ropes in laboratory tanks. The resulting artificial substrates with juvenile sporophytes are explanted to mariculture installations in the sea (Gutierrez et al. 2006; Macchiavello et al. 2010). This method has significant disadvantages, mainly the seasonal restriction and quality of natural spore supply and problems to obtain proper inoculation densities. Furthermore, propagules of epiflora and epifauna introduced with natural spores cause serious fouling problems. Growth rates and harvest biomass per area in such plantations are not satisfactory and subject to erratic variations. These inherent deficits of traditional Macrocystis farming call for fundamentally different novel approaches in Macrocystis mariculture management. Innovations like buildup of permanent genetic stock, standardized seedling production and selection of favourable genotypes are now well under way (Westermeier et al. 2010). These features fulfil the status of "domestication" for the kelp Macrocystis, which can be defined as "the process of hereditary reorganization of wild animals and plants into forms more accommodating to the interests of people" (Anonymous 2010). 
The life history of Macrocystis and related kelps is well studied (Graham et al. 2007). As members of the order Laminariales, they exhibit a biphasic cycle, which alternates between a macroscopic sporophyte and a microscopic gametophyte. Sporophytes are diploid and fixed to the substrate by a multicellular holdfast. Upright growth of fronds is accomplished by apical meristems which differentiate into metre-sized stipes and lateral blades for photosynthesis. Sporophytes enter reproduction by forming sori on fertile blades, where numerous superficial thallus cells undergo meiosis. Huge numbers of sporangia appear, each releasing 32 motile meiospores. Upon fixation to the substrate, spores develop into haploid, few-celled uni-seriate gametophytes. Due to genotypic sex determination, a 1:1 population of female and male gametophytes results, which upon maturity form oogonia and antheridia, producing eggs and spermatozoids, respectively. Under favourable conditions, zygotes and young sporophytes appear a few weeks later.

As a first step towards improved Macrocystis mariculture management, Westermeier et al. (2006) introduced a new laboratory-based culture technique. They started from fieldcollected meiospores and isolated individual gametophytes with favourable properties: good vegetative growth combined with maximum fecundity. Such clonal gametophyte cultures can be maintained and propagated vegetatively in unlimited manner. Gametogenesis can then be initiated at any time by mixing aliquots of both sexes and manipulation of culture conditions. This method allows the production of repeated batches of up to $10^{5}$ juvenile sporophytes. Floating freely under continuous aeration in flasks, cylinders and tanks, they continue to grow and are ready to be explanted to the sea at a length of $8 \mathrm{~cm}$. With this scheme, Westermeier et al. (2006) reached $80 \mathrm{~kg}$ of Macrocystis biomass $\mathrm{m}^{1}$ of rope within 12 months from the start. This compares favourably with $14.4 \mathrm{~kg}$ within 8 months (Gutierrez et al. 2006) and $22 \mathrm{~kg}$ within 5 months (Macchiavello et al. 2010) for traditional mariculture starting from natural spores seeded on ropes.

In order to further improve the potential of laboratorygrown, genetically homogeneous sporophyte seedling batches, some details of reproduction biology in Macro cystis must be considered. Graham (2003) and Raimondi et al. (2004) studied natural Macrocystis beds in California. Meiospores have a limited swimming capacity and settle down near their origin to form gametophytes. Survival of the population requires a high density of gametophytes, since the distance for successful interaction between egg and sperm does not exceed the range of millimetres. Raimondi et al. (2004) estimated that the area within which a given sporophyte can reliably produce new progeny only reaches out a few metres from its basal holdfast. This spatial limitation strongly enhances inbreeding, i.e. zygote formation by gametophytes originating from the same parent individual. In consequence, inbreeding-mediated population senescence may be responsible for spontaneous population oscillations in Californian Macrocystis beds.

From these considerations, it is evident that the Macro cystis inoculants hitherto used for mariculture are likely to be handicapped by inbreeding depression. Both the traditional rope-seeding method as well as the use of one pair of genetically related gametophyte clones for laboratory seedling production are subject to the burden of inbreeding effects. In consequence, outcrossing must be expected to be a promising way to improve the growth characteristics of laboratory-produced Macrocystis seedlings.

In order to evaluate this possibility, Westermeier et al. (2010) carried out a systematic cross-breeding programme with representative gametophyte pairs of Macrocystis pyrifera from seven geographically separated localities in South Chile. They compared the growth performance of all 49 hybrid constructs starting from zygotes up to the age of 10 weeks and found the following results:

- Sporophyte batches produced by intra-population (control) matings exhibited statistically significant differences in their growth potentials on relatively low level, which can be interpreted as a manifestation of inbreeding depression.

- In contrast, sporophyte batches from several outcrossing combinations showed significantly higher growth rates than those of their parents.

These results suggested that Macrocystis sporophytes resulting from outbreeding crosses exhibit heterosis, or hybrid vigour, which is defined as "the superiority of the offspring of a cross between two stocks to the better of the parents" (Paul 1992). Heterosis is an important principle used for crop improvement in terrestrial plants and animal breeding. It is evident that laboratory-based seedling production in Macro cystis now offers the chance to apply heterosis breeding to a marine crop system with commercial significance.

We report here our attempts to verify the potential of heterosis breeding for Macrocystis by following favourable heterozygotic sporophyte constructs through their full commercial mariculture cycles.

\section{Materials and methods}

Table 1 lists the cultivars, origins and collection dates for the Macrocystis gametophyte clones used in this study. It contains a selection of those $M$. pyrifera clones originating from South Chile (p2 to p7) that were recognized as parents of especially successful heterosis crosses in our previous study (Westermeier et al. 2010). For comparison, we added a batch of $M$. pyrifera sporophytes produced by a mixture of gametophytes from a natural spore suspension originating from locality p3. Furthermore, we included one pair of $M$. integrifolia parents from North Chile (i8). 
Table 1 Collection sites, dates and cultivar designations for Macrocystis gametophyte clones

\begin{tabular}{lllll}
\hline Locality/cultivar & Habitat & \multicolumn{2}{l}{ Gametophyte clones } & \multirow{2}{*}{ Collection date } \\
\cline { 3 - 3 } & & Female & Male & \\
\hline p2 & Interior sea & p2f & & Oct 2003 \\
p3 & Interior sea & p3f & p3m & Nov 2002 \\
p3 & Interior sea & Natural spore mix & & 2006 \\
p5 & Open Pacific & & p5m & Jan 1997 \\
p6 & Open Pacific & p6f & & Aug 1999 \\
p7 & Interior sea & p7f & & Feb 2003 \\
i8 & Caldera 27 03' S & i8f & i8m & Nov 2002 \\
\hline
\end{tabular}

For practical reasons and in order to avoid confusion and to keep consistency with our previous reports, we choose here to maintain the traditional Macrocystis species names $M$. pyrifera and $M$. integrifolia (see "Discussion").

Male and female gametophyte clones were maintained in vegetative state under low-irradiation red or white light and propagated by periodic fragmentation as described by Westermeier et al. (2006). Gametogenesis and zygote formation were induced by mixing male and female gametophyte fragments, followed by exposure to increased irradiance with white fluorescent light in combination with a temperature drop to $10^{\circ} \mathrm{C}$. After 3 weeks, juvenile sporophytes had reached millimetre size and were introduced into 1-L gas washing bottles with aeration and magnetic stirring. Sporophyte cultures were successively expanded to 2-, 5- and 10-L bottles and then transferred to Plexiglas cylinders of 20- and $50-\mathrm{L}$ volume. As a final indoor step, sporophyte batches were kept in 800 -L greenhouse tanks with aeration and running natural seawater. At a size of $8 \mathrm{~cm}$, sporophyte seedlings were inserted with their holdfast into fragments of 4-mm polypropylene rope, which were subsequently fixed with plastic clips to $12-\mathrm{mm}$ polypropylene carrier lines for transplantation into the sea (Westermeier et al. 2006).

Three commercial mariculture installations at different parts of the coast of Chile were used for explantation of our experimental sporophyte crosses: Curanue, Chiloé in southern Chile ( $\left.41^{\circ} 08^{\prime} \mathrm{S}\right)$, Bahia Inglesa $\left(27^{\circ} 08^{\prime} \mathrm{S}\right)$ with moderate and Bahia Salado $\left(27^{\circ} 37^{\prime} \mathrm{S}\right)$ with stronger wave exposure in North Chile. All mariculture experiments took place in late winter to early spring. Carrier lines with 6 seedlings $\mathrm{m}^{1}$ were installed horizontally at depths between 4 and $6 \mathrm{~m}$ in the southern site, and 6 to $10 \mathrm{~m}$ in the northern sites. Lateral distance between carrier lines was $1 \mathrm{~m}$. Fresh weight with standard deviation of 10 to 12 randomly selected fronds was determined in monthly intervals up to full harvest size. After 5 months in the sea, the Macrocystis biomass on the ropes had reached its maximum, and the mariculture experiments were terminated.

\section{Results}

The biomass production of our most favourable Macrocystis heterosis constructs is shown in Fig. 1. The M. pyrifera

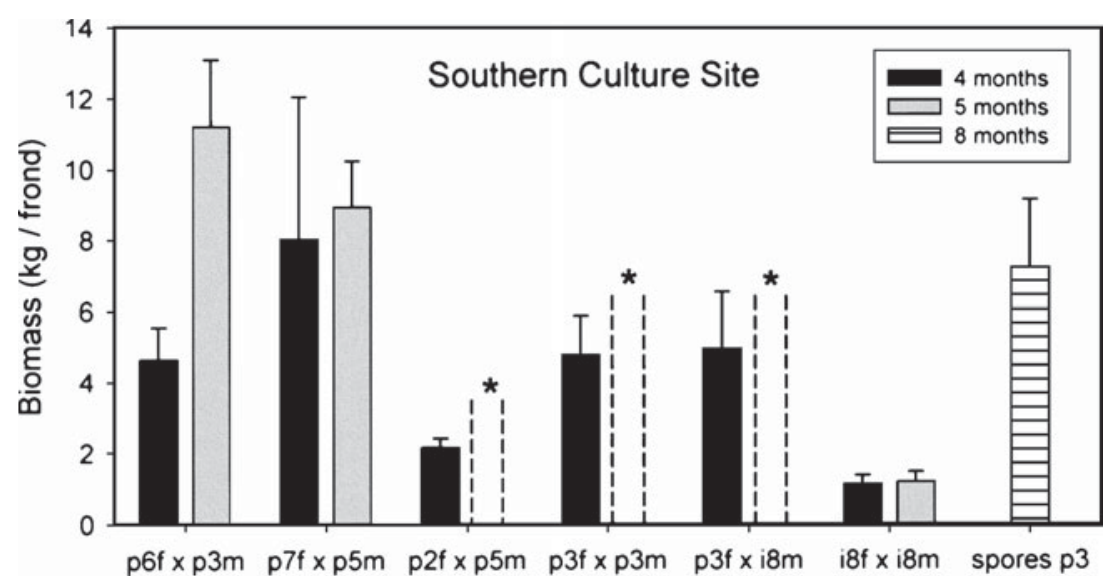

Fig. 1 Biomass production ( $\mathrm{kg}$ per frond, averages and SD from 10 to 12 individuals) by various Macrocystis sporophyte genotypes after 4 and 5 months of exposure in the sea at a mariculture installation in Curanue (South Chile $41^{\circ} 46^{\prime} \mathrm{S}$ ). Extreme right: genotype mixture derived from spores of a field population at locality p3. Cross designations: $p, i$ : M. pyrifera or $M$. integrifolia parent, respectively; numbers refer to location of origin listed in Table 1. $f, m$ : female and male parent, respectively. Asterisks: exact determination of total biomass production at 5 months is not possible because, after 4 months of field exposition, growth coincided with partial loss of biomass 
crosses $\mathrm{p} 6 \mathrm{f} \times \mathrm{p} 3 \mathrm{~m}$ and $\mathrm{p} 7 \mathrm{f} \times \mathrm{p} 5 \mathrm{~m}$ showed the highest biomass, their yield ranging between 9 and $11 \mathrm{~kg}$ fresh weight per frond produced within 5 months of exposure in the field. Two additional M. pyrifera crosses $(\mathrm{p} 2 \mathrm{f} \times \mathrm{p} 5 \mathrm{~m}$ and $\mathrm{p} 3 \mathrm{f} \times \mathrm{p} 3 \mathrm{~m})$ were less productive after 4 months. Although they continued to grow and produce new biomass, substantial loss occurred by mechanical forces due to high stipe and phylloid density. In consequence, their total 5-month biomass production could not be determined correctly.

A suspension of spores, which represented a natural $M$. pyrifera genotype mixture of locality $\mathrm{p} 3$ was subjected to our culture technique of free-floating juvenile sporophytes as a control experiment. Under mariculture field conditions, the thalli reached a good production level of $7 \mathrm{~kg}$ frond ${ }^{1}$ on average. However, this complex genotype mixture needed 8 months to reach a biomass level, which our more potent, genetically homogeneous heterosis constructs produced in only 4 to 5 months.

An intra-cultivar cross $(\mathrm{i} 8 \mathrm{f} \times \mathrm{i} 8 \mathrm{~m})$ representing $M$. integrifolia from Caldera (North Chile) performed rather poorly under South Chile mariculture exposure. However, it showed a fivefold increase in biomass production in the southern Chile climate, when its female parent was substituted by a $M$. pyrifera genotype $(\mathrm{p} 3 \mathrm{f} \times \mathrm{i} 8 \mathrm{~m})$.

Comparison of the results shown in Figs. 1 and 2 points to the influence of climatic factors on the performance of our Macrocystis heterosis constructs. The M. pyrifera cross $\mathrm{p} 7 \mathrm{f} \times \mathrm{p} 5 \mathrm{~m}$ performed as a superior biomass producer under both southern and northern climate conditions. In contrast, the $M$. pyrifera intra-cultivar cross $\mathrm{p} 3 \mathrm{f} \times \mathrm{p} 3 \mathrm{~m}$ appeared significantly reduced under the northern climate regime. In reciprocal fashion, the intra-cultivar cross of $M$. integrifolia i8f $\times$ i8m showed about twice the productivity in its proper northern climate than in the South.

The most productive Macrocystis genotype under North Chile climate conditions was an inter-specific construct with $M$. pyrifera as female and $M$. integrifolia as male parent $(\mathrm{p} 3 \mathrm{f} \times \mathrm{i} 8 \mathrm{~m})$. Nevertheless, an inter-cultivar cross of M. pyrifera reached the same productivity level $(\mathrm{p} 7 \mathrm{f} \times$ p5m) in Bahia Inglesa (Fig. 2).

Influence of site-specific conditions can be inferred by comparing the yields of the constructs $\mathrm{p} 3 \mathrm{f} \times \mathrm{i} \mathrm{m}$ and $\mathrm{p} 3 \mathrm{f} \times$ $\mathrm{p} 3 \mathrm{~m}$ in the two localities Bahia Inglesa and Bahia Salado. Although these two mariculture sites are only $70 \mathrm{~km}$ apart within the same climate zone, up to threefold higher biomass production was obtained in the calm waters of Bahia Inglesa compared with Bahia Salado under stronger wave exposure.

In addition to high yield and rapid growth, our heterosis constructs showed additional favourable characters when grown to full size under mariculture conditions. Due to the genetical homogeneity of our defined sporophyte genotypes, mariculture plantations appeared strikingly uniform: all fronds of a given genotype had similar size and blade morphology (Figs. 3 and 4). Likewise, Figs. 5 and 6 illustrate homogeneity of holdfast expression in a given genotype. Figures 5 and 7 indicate that our inoculation density of 6 seedlings $\mathrm{m}^{1}$ of line seems appropriate and likely to guarantee maximum use of rope length and available space. Finally, at harvest stage, the mariculture crops of all our highly productive heterosis constructs appeared remarkably clean, with negligible evidence for herbivory or fouling by epifauna and epiflora (Figs. 5 and 7)

\section{Discussion}

\section{Macrocystis taxonomy}

Taxonomy within the genus Macrocystis is presently under dispute. Traditionally, based on morphological characteristics, four species are recognized: $M$. pyrifera, $M$. integrifolia, M. angustifolia and M. laevis. Recent molecular data, however, did not support this distinction (Coyer
Fig. 2 Biomass production $(\mathrm{kg}$ per frond, averages and SD from 10 to 12 individuals) by various Macrocystis sporophyte genotypes after 4 and 5 months of exposure in the sea at two locations in North Chile: Bahia Inglesa $\left(B I, 27^{\circ} 08^{\prime} \mathrm{S}\right)$ and Bahia Salado $\left(B S, 27^{\circ} 37^{\prime} \mathrm{S}\right)$. Cross designations as in Fig. 1. Asterisks: same as in Fig. 1

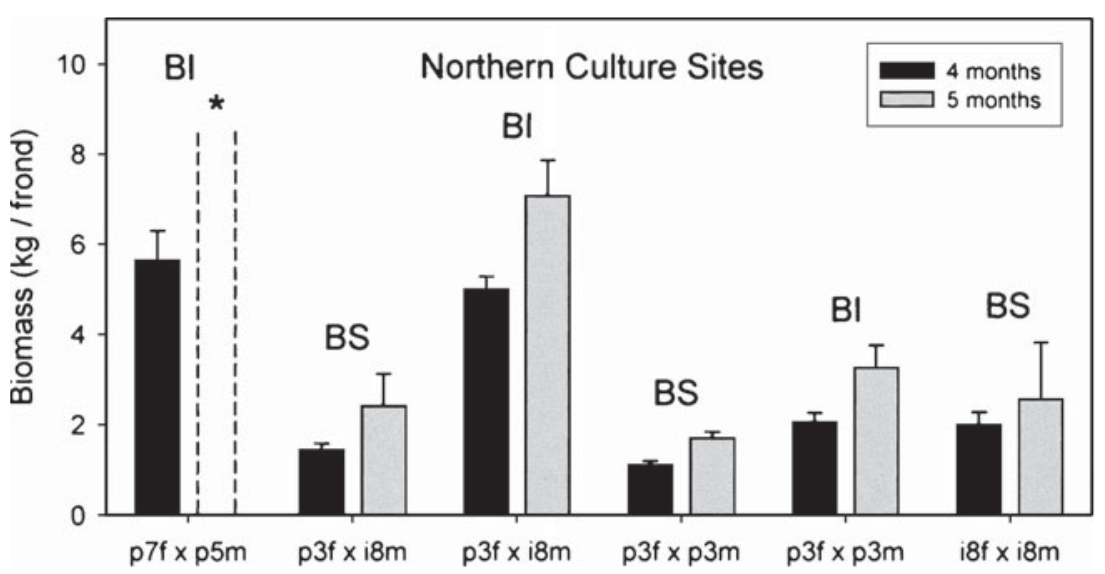


Fig. 3 Appearance of some Macrocystis heterosis constructs in mariculture installations. Cross designations as in Fig. 1. Cross $\mathrm{p} 7 \mathrm{f} \times \mathrm{p} 5 \mathrm{~m}$ after 1 month in the sea at Curanue (South Chile) Fig. 4 Appearance of some Macrocystis heterosis constructs in mariculture installations. Cross designations as in Fig. 1. Same cross, same locality after 5 months in the sea Fig. 5 Appearance of some Macrocystis heterosis constructs in mariculture installations. Cross designations as in Fig. 1. Cross p6f $\times$ p3m after 4 months in the sea at Curanue

Fig. 6 Appearance of some Macrocystis heterosis constructs in mariculture installations. Cross designations as in Fig. 1. Same cross, same locality at 5 months. Close up of hypertrophic holdfasts amounting up to $600 \mathrm{~g}$ fresh weight per individual

Fig. 7 Appearance of some Macrocystis heterosis constructs in mariculture installations. Cross designations as in Fig. 1 Inter specific cross $\mathrm{p} 3 \mathrm{f} \times \mathrm{i} 8 \mathrm{~m}$ after 5 months in the sea at Bahia Inglesa (North Chile)
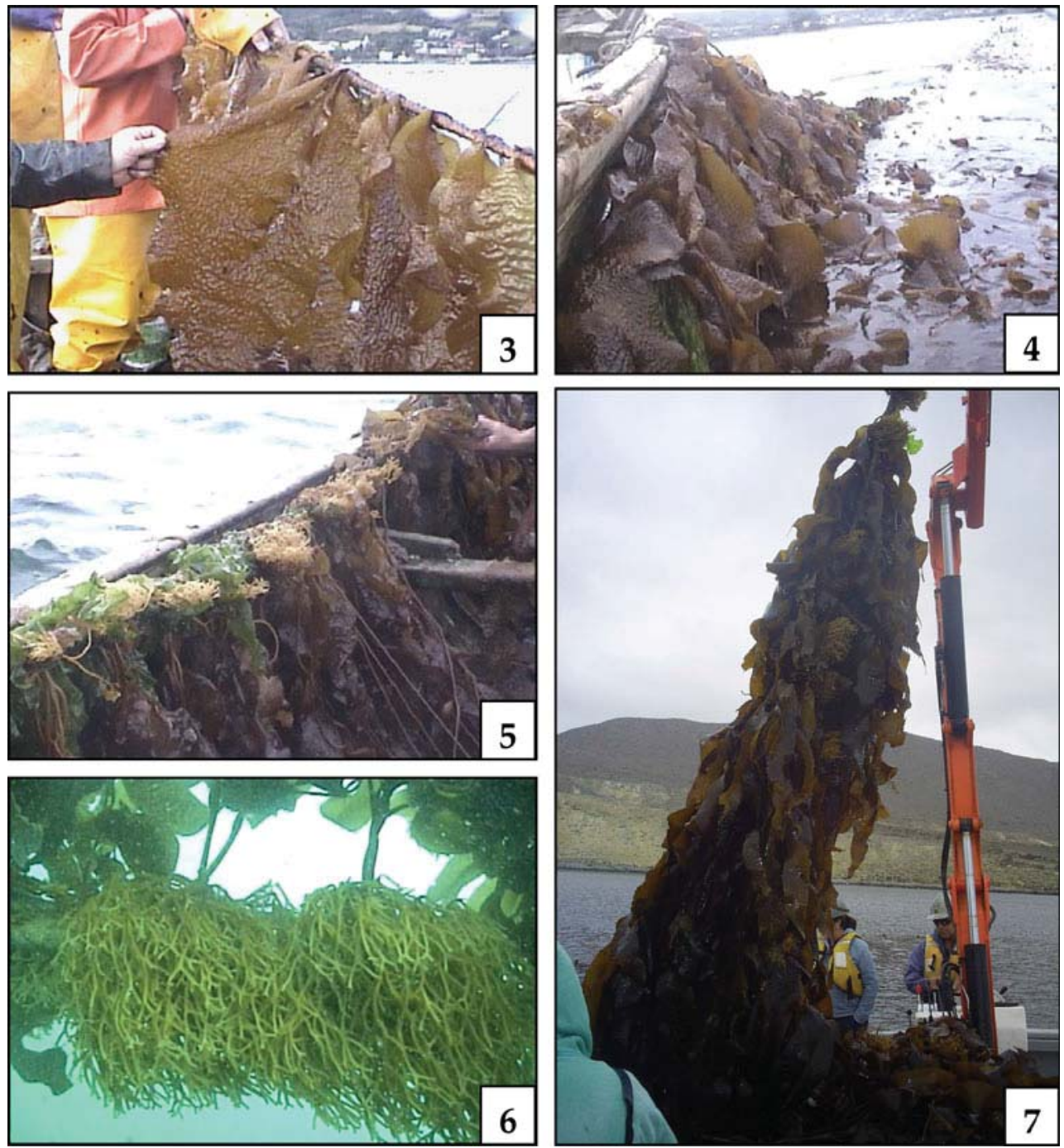

et al. 2001). Demes et al. (2009) suggested that high phenotypic plasticity might be responsible for morphological differences and proposed that the four taxa should be merged under the single species $M$. pyrifera. This interpretation fits with our own experimental results that $M$. pyrifera and $M$. integrifolia at the coast of Chile are interfertile and able to produce functional meiotic offspring. However, the clear geographic separation of the two taxa, with a transition zone between Concepcion and Valparaiso (Westermeier et al. 2007), remains still unexplained. All Macrocystis isolates used for our breeding studies originated from locations well within the distribution ranges of $M$. pyrifera in the South and M. integrifolia in the North, and the specific morphological characters of their parent specimens were undisputable. We find it important to maintain these informations on the origin and character of our stock collection and to keep the continuity with our previous materials and results. Therefore, we have chosen to use the traditional species names until the two taxa will be formally downgraded to a proper sub-specific level.

Heterosis in agricultural crops and kelps

Heterosis, also known as "hybrid vigour," may be defined as "a genetic state in which hybrids are superior to their parents with respect to a certain character" (Belea 1992). This principle has been studied since the end of the nineteenth century, and maize was one of the first important crops in which heterosis was commercially applied. Various mechanisms (dominance, overdominance and epistasis) are discussed as the genetic basis of heterosis (Banga 1998; Welsh 1981). In terrestrial crops such as maize, which are diplonts, two parental parent lines must be established and maintained in order to produce the seeds for the high-performance hybrid generation. The construction of these parent genotypes requires complicated, time-consuming procedures and 
repeated back-crossing. In contrast, the selection of a heterosis parent pair is an easy and one-step process in kelps because the parent lines are stable, haploid, free-living gametophytes which can be propagated vegetatively.

Heterosis in a member of the Laminariales has been first described for Undaria pinnatifida, a commercially interesting kelp in Japan (Hara and Akiyama 1985). More recently, closely related Laminaria species were crossed in order to produce superior genotypes in China (Zhang et al. 2007; Li et al. 2007). Li et al. (2008) used molecular techniques to correlate genetic distances between Lami naria parent lines and economically interesting characters of their heterosis products. Our results show that Macro cystis will now be a new candidate, offering the potential of heterosis breeding in another economically interesting kelp species.

Favourable properties of Macrocystis heterosis constructs

The results of our study show that heterosis, jointly with indoor seedling production, can be used to provide favourable stocks of Macrocystis genotypes with features that are apt to increase the productivity and versatility of mariculture enterprises:

- Higher biomass production $\left(66 \mathrm{~kg} \mathrm{~m}^{1}\right.$ of rope within 4 to 5 months, in contrast to $14.4 \mathrm{~kg} \mathrm{~m}^{1}$ after 8 months (Gutierrez et al. 2006), and $22 \mathrm{~kg} \mathrm{~m}^{1}$ after 5 months (Macchiavello et al. 2010) under traditional management)

- Faster growth rates, reaching maximum harvest biomass within 4 to 5 months. This speed-up opens the option to produce two harvests per year

- Due to genetic homogeneity, crops of a given genotype appear morphologically uniform, and available space can be used to maximum efficiency

- Our laboratory-based seedling production by quasiaseptic growth conditions until explantation of seedlings to the sea seems to drastically reduce the buildup of pathogens and fouling

- Highly productive genotypes may be selected with specific morphological properties such as haptera hypertrophy (Fig. 6), high proportion of foliose biomass or other characters

- Among our heterosis constructs, we detected aberrant genotypes with different protein and lipid contents, which might be selectively used for specific demands (Westermeier, unpublished)

Maintenance of genetic stocks for commercial heterosis breeding

Long-term success of a commercial kelp biomass production project depends strongly on the reliable and long-term availability of high-performance breeding stocks. Laminarialean gametophytes are perennial stages and able to survive for years under a low-irradiance light regime. The oldest representatives in our stock collection are a pair of male and female $U$. pinnatifida gametophytes isolated in 1972 and maintained in liquid culture medium. When stimulated to gametogenesis in 2010, after 38 years in culture, they were found to be fully potent, forming zygotes and embryos (Müller, unpublished observation). Likewise, numerous Macrocystis and Lessonia gametophyte clones from Chile in our collection are fully fertile after 10 years in culture. These observations indicate that laminarialean gametophytes may be expected to survive for decades in culture without losing their reproductive potential.

Müller et al. (2008) proposed a further progress in gametophyte conservation, which allows the total exclusion of microbes from cultures. Gametophytes of Lessonia and Macrocystis can be grown on agar plates, and contaminants removed by antibiotic treatment. This axenic maintenance technique improves the long-term availability and stability of Macrocystis gametophyte stock. Finally, Zhang et al. (2008) showed that gametophytes of Laminaria japonica can be successfully subjected to cryo-preservation. It appears likely that this method will also be applicable to Macrocystis, thus offering maximum chances for long-time availability and stability of commercially interesting kelp breeding stocks.

In summary, the innovations on Macrocystis domestication reported here constitute a sound base to establish modern and highly productive mariculture regimes in Chile.

Acknowledgements This study was supported by FONDEF DO4I 1288 (CONICYT CHILE). We thank the companies HIDROCULTIVOS S.A., HGUA S.A. and CERNAMAR for cooperation. L. Muñoz, A. Ruiz and C. Atero, Puerto Montt, contributed with field and laboratory activities, and H. Müller, Konstanz with art work. Thanks are also due to two anonymous reviewers who contributed valuable suggestions.

\section{References}

Anonymous (2010) "Domestication." Britannica Concise Encyclopedia, http://www.answers.com/library/Britannica+Concise+Encyclopedia cid 3047010

Banga SS (1998) Heterosis: an introduction. In: Banga SS, Banga SK (eds) Hybrid cultivar development. Springer, Berlin, pp 116

Belea A (1992) Interspecific and intergeneric crosses in cultivated plants. Akadémiai Kiadó, Budapest

Coyer JA, Smith GJ, Anderson RA (2001) Evolution of Macrocystis spp. (Phaeophyceae) as determined by ITS1 and ITS2 sequences. J Phycol 37:574 585

Demes KW, Graham MH, Suskiewicz TS (2009) Phenotypic plasticity reconciles incongruous molecular and morphological taxonomies: the giant kelp, Macrocystis (Laminariales, Phaeophyceae), is a monospecific genus. J Phycol 45:1266 1269 
Graham MH (2003) Coupling propagule output to supply at the edge and interior of a giant kelp forest. Ecology 84:1250 1264

Graham MH, Vasquez JA, Buschmann AH (2007) Global ecology of the giant kelp Macrocystis: from ecotypes to ecosystems. Oceanogr Mar Biol Ann Rev 45:39 88

Gutierrez A, Corres T, Muñoz V, Santibañez A, Marcos R, Cáceres C, Buschmann AH (2006) Farming of the giant kelp Macrocystis pyrifera in southern Chile for development of novel food products. J Appl Phycol 18:259 267

Hara M, Akiyama K (1985) Heterosis in growth of Undaria pinnatifida (Harvey) Suringar. Bull Tohoku Reg Fish Res Lab 47:47 50

Li X, Cong Y, Yang G, Shi Y, Qu S, Li Z, Wang G, Zhang Z, Luo S, Dai H, Xie J, Jiang G, Liu J, Wang T (2007) Trait evaluation and trial cultivation of Dongfang No. 2, the hybrid of a male gametophyte clone of Laminaria longissima (Laminariales, Phaeophyta) and a female one of L. japonica. J Appl Phycol 19:139 151

Li X, Yang G, Shi Y, Cong Y, Che S, Qu S, Li Z (2008) Prediction of the heterosis of Laminaria hybrids with the genetic distance between their parental gametophyte clones. J Appl Phycol 20:1079 1102

Macchiavello J, Araya E, Bulboa C (2010) Production of Macrocystis pyrifera (Laminariales; Phaeophyceae) in northern Chile on spore based culture. J Appl Phycol. doi:10.1007/s10811 010 95088

Müller DG, Gachon CMM, Küpper FC (2008) Axenic clonal cultures of filamentous brown algae: initiation and maintenance. Cah Biol Mar 49:59 65
Paul D (1992) Heterosis. In: Keller EF, Lloyd EA (eds) Keywords in evolutionary biology. Harvard Univ Press, Cambridge, pp 166169 Raimondi PT, Reed DC, Gaylord B, Washburn L (2004) Effects of self fertilization in the giant kelp Macrocystis pyrifera. Ecology $85: 32673276$

Vásquez JA (2008) Production, use and fate of Chilean brown seaweeds: resources for sustainable fishery. J Appl Phycol 20:457 467

Welsh JR (1981) Fundamentals of plant genetics and breeding. Wiley, New York

Westermeier R, Patiño D, Piel MI, Maier I, Müller DG (2006) A new approach to kelp mariculture in Chile: production of free floating sporophyte seedlings from gametophyte cultures of Lessonia trabeculata and Macrocystis pyrifera. Aquaculture Res 37:164 171

Westermeier R, Patiño D, Müller DG (2007) Sexual compatibility and hybrid formation between the giant kelp species Macrocystis pyrifera and $M$. integrifolia (Laminariales, Phaeophyceae) in Chile. J Appl Phycol 19:215 221

Westermeier R, Patiño D, Müller H, Müller DG (2010) Towards domestication of giant kelp (Macrocystis pyrifera) in Chile: selection of haploid parent genotypes, outbreeding, and heterosis. J Appl Phycol 22:357 361

Zhang Q, Tang X, Cong Y (2007) Breeding of an elite Laminaria variety 901 through inter specific gametophyte crossing. J Appl Phycol 19:303 311

Zhang Q, Cong Y, Qu S, Luo S, Yang G (2008) Cryopreservation of gametophytes of Laminaria japonica (Phaeophyta) using encapsulation dehydration with two step cooling method. J Ocean Univ China 7:65 71 